\title{
Stability Assessment of Historic Plaster Ceilings on Wood Lath
}

\author{
Helena M. Currie, Matthew B. Bronski, and Rachel M. Lynde
}

Simpson Gumpertz \& Heger, Inc. (SGH), 480 Totten Pond Road, Waltham, Massachusetts 02451, United States of America, HMCurrie@sgh.com, MBBronski@sgh.com, RMLynde@sgh.com

\begin{abstract}
Plaster (often lime plaster, reinforced with animal hair) installed on wood lath secured to wood framing was a common ceiling system for hundreds of years in the Americas, and for thousands of years in Europe. Despite having a relatively good record of stability, some ceilings of this type have collapsed. Given their overhead position, often above large groups of people, when cracks or localized areas of displacement or damage occur in these ceilings, the question often arises as to whether the ceiling is stable and safe. Because procedures for stability assessment of historic plaster ceilings on wood lath are not well quantified in building codes or technical literature, this article proposes key considerations and best practices for assessing these ceilings.
\end{abstract}

Keywords: Historic, Plaster Ceilings, Condition Assessment, Structural Stability, Vibration Monitoring.

\section{Typical Construction}

Plaster ceilings on wood lath were a common ceiling system for hundreds of years in the Americas, and for thousands of years in Europe. European plaster ceilings typically consist of lime-based plaster (lime and sand) that is reinforced with animal hair, applied to a network of narrow, closely spaced wood members, that are secured to an overlying structural framework of larger wood members, either by tying in the earlier examples, or nailing in the later examples. Similar plaster ceilings applied to dried wood reeds (aka wattle, or wicker) were constructed over 2,000 years ago, as described by the Roman architect Vitruvius in the first century BCE in his treatise De Architectura [Vitruvius]. Multiple 500 year-old examples of this plaster ceiling construction survive from the Italian Renaissance.

Historic examples in the USA survive from as early as the mid- $18^{\text {th }}$ century, and were typically constructed of lime-based plaster with animal hair fibers (Fig. 1A), similar to earlier European examples; however, closely spaced wood members are lath (long slender wood pieces) rather than dried reeds. Prior to the early $19^{\text {th }}$ century, the wood lath was typically riven (i.e., hand-split), and from the early $19^{\text {th }}$ to the early $20^{\text {th }}$ century, the wood lath was typically sawn. In both cases, pieces of the wood lath were approximately $6 \mathrm{~mm}$ thick by $60 \mathrm{~mm}$ wide, with gaps approximately $6 \mathrm{~mm}$ wide between the long edges in sawn lath, and approximately 2-6 mm wide between the long edges of riven lath. The lath is secured to the overlying structural wood framing (e.g., the floor framing of the roof or attic above) by smooth shank nails, installed from the underside. Prior to the late $19^{\text {th }}$ century, the nails were either hand-forged wrought nails or cut nails, which both have a wedge-shaped profile, tapering from head to tip. After the late $19^{\text {th }}$ century, the nails are typically wire nails, which have a uniform cylindrical shank and a point only at the tip.

In both European and US examples, the dense network of slender wood members (dried reeds or lath) are intentionally spaced with gaps between the long edges to provide space for the wet plaster to be forced between the gaps and create hardened plaster "keys" on the topside 
of the lath or reeds, that are wider than the gaps, and thus form lines of mechanical interlock between the plaster and the topside of the reeds or lath. In both European and US examples, whether tied or nailed from below, the connection of the dried reeds or wood lath to the overlying structural wood framing is a tensile connection.

\section{Typical Failure Modes}

Failures of these historic plaster ceilings in the US typically fall into one of two primary failure modes: 1) failure of plaster keys (Fig. 1B), or 2) tensile failure or "pull-out" of the nailed connections of the lath to the overlying wood framing (Fig. 1C).

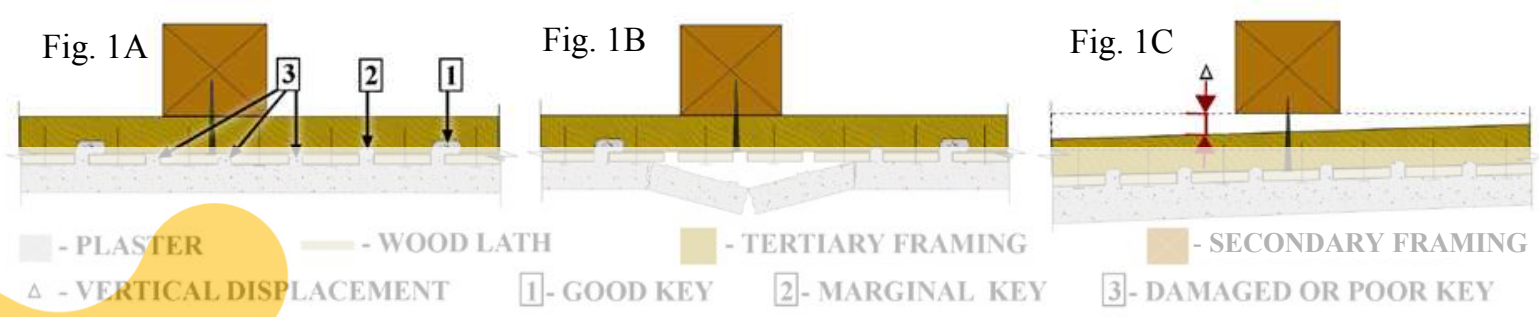

Figure 1. Typieal historic plaster ceiling construction on wood lath (Fig. 1A) and two primary failure modes: plaster key failure (Fig. 1B) and fastener "pull-out" (tensile) failure of supporting framing connections (Fig.1C).

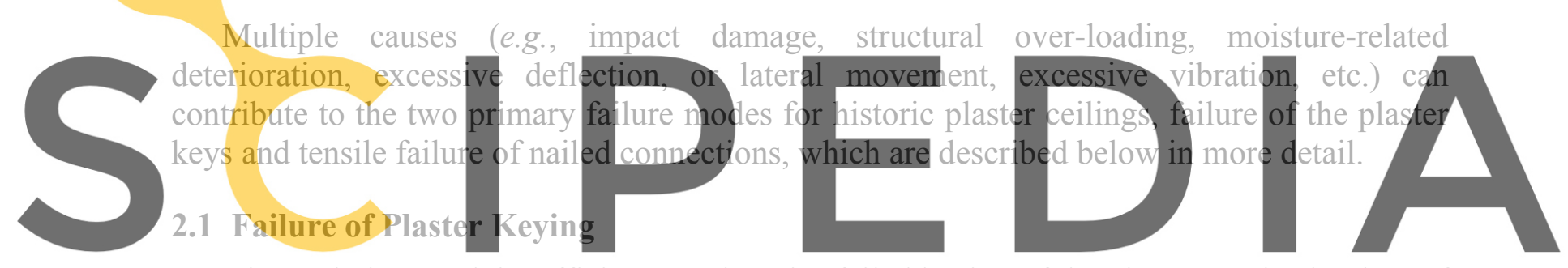

Deteriorated, damaged, insufficient or otherwise failed keying of the plaster can lead to loss of

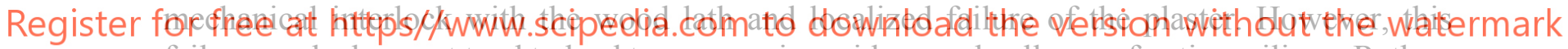

failure mode does not tend to lead to progressive widespread collapse of entire ceilings. Rather,

this failure tends to be self-arresting. As unkeyed, debonded plaster starts to separate and displace downward from the wood lath, the self-weight of the debonded area may exceed the remaining interlock capacity of the remaining plaster keys, if any, and cause a relatively small $\left(<0.1 \mathrm{~m}^{2}\right)$ displaced piece to break off (as a result of the low shear strength and flexural strength of the plaster) before the displaced piece becomes relatively large (Fig. 1B). Generally, this failure mode tends to result in the falling of relatively small pieces of plaster alone (with no wood lath or framing). Given the light weight and friability of the lime plaster, plaster pieces of this size $\left(<0.1 \mathrm{~m}^{2}\right)$ generally do not pose a significant life safety risk when they fall. When evaluating the condition of plaster keys, it is helpful to distinguish between the original condition and current condition of the plaster keys, because the severity and extent of currently damaged keys, compared to the condition and performance of the original plaster keys, will inform to what extent one can or cannot rely on the track record of performance of the keying as testament to its current stability.

Original Adequacy of Plaster Keys: The adequacy of the plaster keying through the lath, as originally constructed, depends on how well-keyed (mechanically interlocked) it is with the topside of the wood lath to which it is applied. Substantially interlocked plaster keys are clearly 
wider than the corresponding gap in the lath, and thick enough where they pass over the back edge of the lath to resist a shear or flexural failure within the plaster key. Keys that are at least twice the width of the gap, and with a thickness of plaster of at least $6 \mathrm{~mm}$ above the top edge of the lath, we consider to be "good" keys. By contrast, we consider "marginal" keys to be barely wider than their corresponding gap in the lath, with minimal thickness (less than $6 \mathrm{~mm}$ ) where they pass over the top edge of the lath. We consider "poor" keys to be equal to or less than the width of their corresponding gap in the lath. In any ceiling installation, the best keys tend to occur at more vertical portions of the ceiling, where the wet plaster keys were applied with more ease and sagged down and over the topside/backside of the wood lath during the original installation. In the more horizontal portions of a plaster ceiling, where gravity does not aid in the formation of keys, good keying was achieved only when the workers forced sufficient plaster through the gaps in the lath with sufficient hand pressure on the trowel. Thus, the quality of the original keying in horizontal (overhead) conditions relied heavily on workmanship.

A common approach in evaluating ceilings is to conservatively consider marginal keys as not contributing to the reliability of the plaster ceiling attachment. However, in our experience, reviewing the performance of plaster ceilings a century or more old, good keys are quite reliable, and even marginal keys may perform well long-term. One historic ceiling we examined that is constructed primarily of marginal keys has performed relatively well for 200+ years, with only a few highly localized failures (e.g. locations where less than $0.1 \mathrm{~m}^{2}$ pieces of plaster have fallen from the ceiling). While clearly not as strong or reliable as "good" plaster keys, marginal plaster keys likely still contribute to the reliability of the plaster ceiling attachment unless there is evidende of marginal key failure
is no definitive research indicating whother "p
capacity of the ceiling attachment through fric
wood lath, we conservatively consider "poor"
reliability of the plaster ceiling attachment, unless site-specific testing is performed.

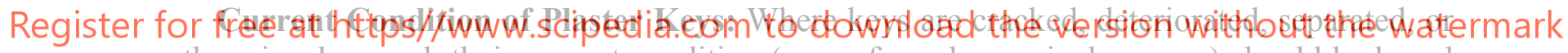
otherwise damaged, their current condition (e.g., of good, marginal or poor) should be based on their remaining intact section, rather than their original width or thickness. In cases where relatively little damage has occurred to the keys since their original construction, one can more reasonably rely on the track record of performance of the keying as a testament to its current stability, since the adequacy of the keying has not been significantly diminished. Conversely, in cases where extensive damage has occurred to the keys since their original construction, one cannot reasonably rely on the track record of performance of the keying.

\subsection{Failure of Supporting Wood Framing}

Failure of the overlying structural wood framing, and/or its connections can potentially lead to progressive collapse of the entire plaster ceiling. Indications of this failure mode are often visible at the topside plaster framing and include gross withdrawal ("pull-out") of nailed wood-wood connections (often smooth shank or tapered nails), or gross displacement of wood members or connections (Fig. 1C). When an individual connection pulls out, the loads and stresses tend to redistribute to the adjacent connections, potentially causing them to become overstressed and more likely to pull out, which can cause a "domino effect" leading to 
progressive collapse of the entire plaster ceiling (i.e., the plaster, wood lath and wood framing, not just the plaster). As such, this failure mode presents a far more significant risk to life safety than the more common (and generally self-arresting) failure mode of inadequate plaster keying.

\section{Stability Assessment: Current Common Practices}

Numerous publications we reviewed emphasize that visual survey is the initial step for plaster evaluation. However, visual survey of plaster is subjective and damage is not consistently defined. Multiple publications also agree that damage visible at the underside of a plaster ceiling often correlates with damage on the topside of the plaster ceiling (Stewart H., 2011; Goeke, 2008). While some practitioners employ destructive tactile tests (i.e., prying of plaster keys from the topside with light hand pressure to determine whether the plaster breaks) to evaluate topside conditions, in our opinion this test is problematic and ill-advised because it is destructive, non-qualitative and highly subjective. If deemed necessary, hands-on assessment, testing, and/or instrumented monitoring may supplement the initial visual assessment of plaster.

Current literature does not clearly define the condition of plaster keys (e.g., "good", "fair", "poor"). While most publications agree that the percentages of damaged plaster keys are an approximate indicator of the overall condition of the plaster (Stewart. R, 2013), percentages that define plaster conditions vary widely in currently available literature, ranging anywhere from 30\%-70\% loss of plaster keys in a given area as meriting repair. Further, the pattern of plaster damage (e.g. whether plaster key loss is highly concentrated or uniformly distributed

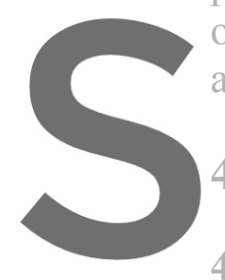
over a given area) that distingulishes "good" fro
as a factor in the overall condition or stability
4 Recommended Best Practices for S

4.1 Three Step Approach to Thitial Visual Assessmemt
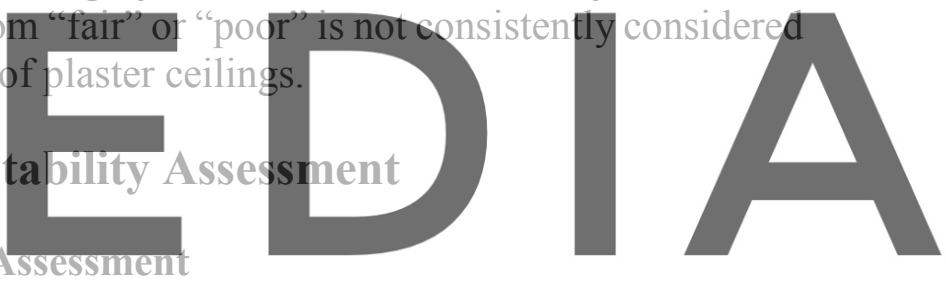

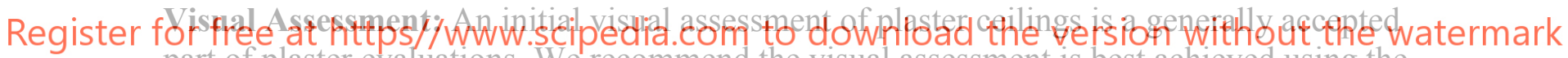
part of plaster evaluations. We recommend the visual assessment is best achieved using the following three step approach:

- Visual review of the underside plaster surface to document cracking and out-of-plane displacement (e.g., sagging, vertical offsets) that may indicate damage or deterioration. This survey is best done first, so that areas of damage at the underside can be examined more closely and correlated with damage identified at the topside.

- Visual review of the topside wood framing to document any indications of gross withdrawal ("pull-out") of nailed wood-wood connections, or gross displacement or deterioration of wood members or connections.

- Visual review of the topside plaster keys to categorize the adequacy of mechanical keying of the plaster into the lath as good, marginal or poor (as previously defined).

Correlating Visual Review of Plaster keys with Tactile Assessment: The visual assessment of the topside plaster should include gentle, non-destructive tactile assessment of a localized area of plaster keys, after a visual-only assessment of the same area. The goal is to correlate the two methods in a representative area and confirm that the visual-only survey of 
the plaster keys does not overlook concealed damage to plaster keys that was found in the tactile survey. If visual and tactile assessment of representative areas yield similar results, proceeding with a visual-only survey (with intermittent tactile testing) is appropriate.

Documenting Current Conditions: Clear, consistent documentation of the existing conditions is critical. Documentation should include clear definitions of each condition (e.g., good, marginal, poor), and indicate the location and condition of keys or panels. Any imminent safety hazards should be identified on-site during the visual assessment, not postponed until synthesis.

\subsection{Additional In-Situ Testing or Monitoring}

In-situ "pull" testing (tensile testing conducted from the underside) of representative types of keys and derivative calculation to determine the actual factor of safety in representative areas can be used to refine the initial approximate criteria for critical percentages of plaster damage with respect to stability. If the ceiling is vaulted, it is preferable to conduct pull tests data on both horizontal and approximately vertical applications of each plaster condition type to get the full range of existing conditions. Pull-testing is most prudent when conservative assumptions and approaches would otherwise lead to invasive recommendations. If vibrations are suspected to be contributing to plaster damage, vibration monitoring may be prudent (Section 5).

\subsection{Synthesis}
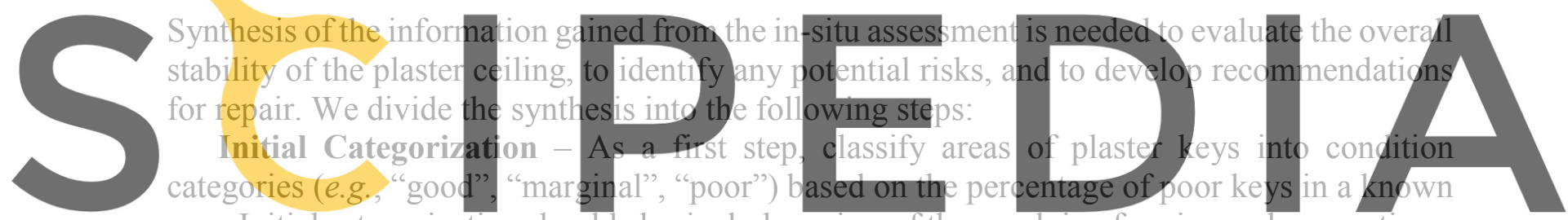

area. Initial categorization should also include review of the overlying framing and connections.

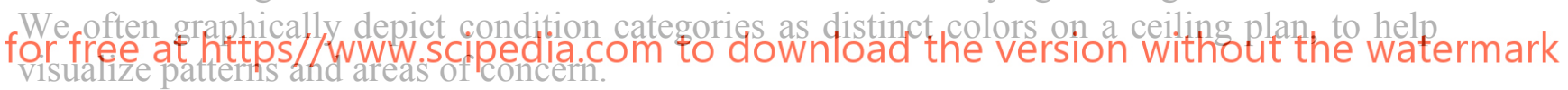

Review Performance History - Understand the performance history (i.e., "track record") of how the plaster keying has performed over time (e.g., few or many areas of previous repair or fallen plaster) to evaluate to what extent undamaged original keying can be relied upon, especially undamaged original "marginal" keys. Compare the current conditions to those of other plaster ceilings of similar construction and the track records of those ceilings.

Assess Sources of Deterioration - For areas where plaster and/or supporting framing is deteriorated or damaged, assess whether source(s) for deterioration are active (e.g., a roof leak), and if so, whether they can be mitigated.

Calculate the Factor of Safety - To assess whether plaster keying conditions are at risk of failure, calculate the ceiling-specific factor of safety for the range of typical conditions and orientations present. The factor of safety (FS) under gravity-loading conditions (not seismic) consists of $\mathrm{FS}=\mathrm{P}_{\mathrm{ff}} / \mathrm{P}_{\mathrm{sw}}$, where $\mathrm{P}_{\mathrm{fl}}$ is the failure load applied to the plaster during the tensile "pull" test, and $\mathrm{P}_{\mathrm{sw}}$ is the self-weight of the plaster for the same surface area. Standard structural engineering procedures and calculations can be used to evaluate the safety and stability of the supporting wood framing and connections. 


\section{Recommended Best Practices for Vibration Monitoring}

\subsection{Standards for Protection of Historic Buildings from Vibration Damage}

There are numerous guidelines and publications for the protection of historic buildings from vibrations; however, various factors make it difficult to directly apply the criteria in these guidelines to evaluating the stability of historic plaster ceilings:

- Criteria for minimizing the probability of damage to existing buildings vary widely (e.g., typical values for peak particle velocity range from 0.06 to $2.0 \mathrm{in} . / \mathrm{sec}$.).

- Criteria tend to be conservative, in that they are typically created to define low vibration levels at, or below, which damage almost certainly will NOT occur, to be relatively certain that vibrations from nearby construction will not damage an historic building. Thus, they are NOT intended to define a threshold at which damage WILL occur.

- Furthermore, these criteria tend to be based on vibration measurements taken at grade outside the historic building, closer to the external source of vibration, not inside the building or at a plaster ceiling itself (where the same external vibrations would measure at lower levels). Thus, these criteria are even more conservative when applied to internal vibration sources as measured at the interior.

Based on our review of various articles (Johnson, Hannen), as well as common vibration standards (e.g., the British, German, and Swiss Standards), the vibration guideline values listed in the Swiss Standard for Building Class 4 (i.e., the most sensitive class for historic and protected buildings) is often referred to as the most appropriate standard for evaluation of historic or sensitive $m$ generally more conservat most conservative vibrati as the threshold vibration limit for monitoring a aesthetic or structural damagd will occur if vibration levels
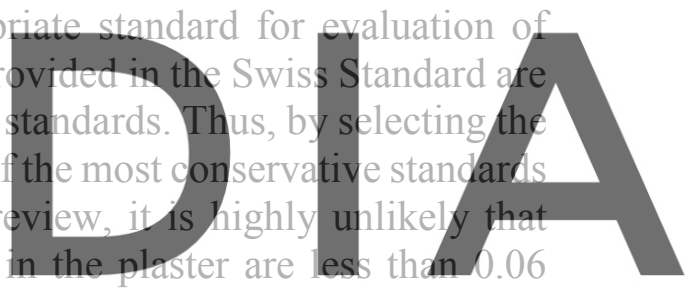

in./sec. Because the Swiss Standard and others are not directly applicable and likely highly

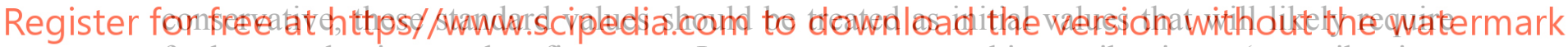
further evaluation and refinement. In some cases, ambient vibrations (i.e. vibrations experienced by the plaster ceiling regularly) or anticipated vibrations exceed these conservative limits. In these cases, project-specific vibration monitoring and/or testing may allow lessconservative project-specific threshold vibration criteria to be established for specific ceilings.

\subsection{Continuous and Discrete Vibration Monitoring}

A successful vibration monitoring program must achieve two primary objectives: 1) quantify the vibration levels experienced by the plaster over time and 2) evaluate specific vibration sources that pose a potential risk of damaging the plaster. Continuous vibration monitoring over an extended period of time, at the point of interest (i.e. at the topside of the plaster) quantifies both the ambient (typical) and atypical vibrations at the plaster ceiling. When ambient vibrations fall below the conservative industry thresholds, vibrations are highly unlikely to cause plaster damage. Where ambient vibrations levels are higher than these thresholds, however, vibrations will not necessarily cause damage to the ceiling. By contrast, this may confirm that the industry standard vibration criteria are not appropriate. Additionally, the type 
and regularity of occurrence for each vibration source that coincides with high vibration levels should be taken into consideration (some standards do not account for these factors).

All potential vibration sources identified during continuous monitoring as exceeding the ambient or industry-standard threshold should be further assessed by discrete vibration testing of those specific sources, isolated to the greatest extent possible. Consider vibration monitoring information jointly with the plaster condition assessment to determine whether any of the plaster damage is likely associated with suspect vibrations sources. For example, where damaged plaster keys are highly concentrated adjacent to walkways at the topside of the ceiling, vibration monitoring can help to evaluate whether the damage is from accidental direct impact (e.g., individuals bumping into the plaster) or transferred vibrations (e.g., from footsteps on the walkway transmitted through rigid connections to the ceiling framing) (Fig. 2).

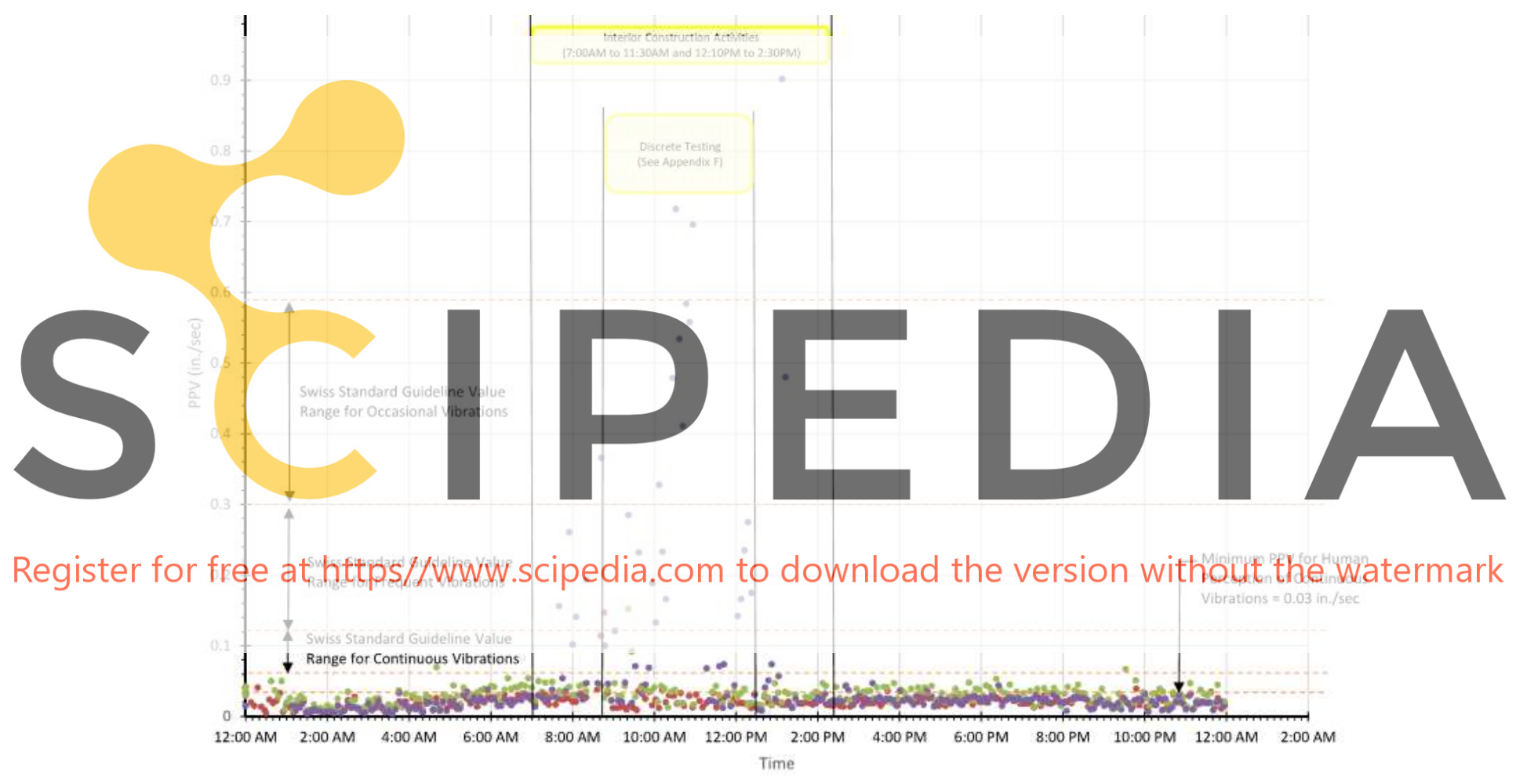

Figure 2. Example of vibration measurements collected at the topside of a plaster ceiling (where plaster damage was concentrated adjacent to attic walkways) during targeted vibration monitoring of an historic plaster ceiling.

In turn, this diagnosis should inform the recommendations to mitigate the problem (e.g., implementing a protection system to mitigate accidental impact, or developing a dampening system to mitigate walkway vibrations, respectively).

\section{Conclusion}

Historic plaster ceilings on wood lath have been used for thousands of years, in many countries on multiple continents, and are a valuable historic resource well worth preserving. Despite some failures, plaster ceilings on wood lath generally have a reliable track record. The two most 
common failure modes are failure of plaster keys and failure or "pull-out" of the supporting wood framing, the latter of which can result in progressive or whole-sale collapse. While vibrations are seldom the driving mechanism for failure, vibration monitoring is helpful in some cases where vibrations are a suspected cause of damage. In the US, the lack of guidelines or standards on how to evaluate historic plaster ceiling stability, and relatively little technical literature on the topic has been a hindrance to their proper evaluation of life safety/stability. Based on our experience, we utilize and recommend the condition and stability assessment procedure described herein, which includes documenting the original and current condition through visual assessment and correlation of visual observations with intermittent tactile assessment and empirical comparisons, in-situ testing and/or monitoring where prudent, and development of evaluation criteria and recommendations through post-processing and synthesis.

\section{ORCID}

Helena M. Currie: https://orcid.org/0000-0001-8991-7226

Matthew B. Bronski: https://orcid.org/0000-0002-6360-3226

Rachel M. Lynde: https://orcid.org/0000-0003-1639-8896

\section{References}

British Standard: Evaluation and Measurement for Vibrations in Buildings, Part 2 ( 1993). BS 7385-2.

Deutsch Norm (German Standard) DIN 4150-3: Erschutterungen im Bauwesen - Teil 3: Einworkungen auf

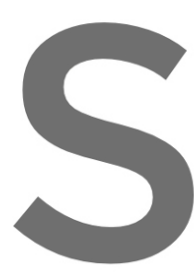
bauliche Antagen, (Strin Translation. Berlin, Gd

Giovanetti, F., ed. (1997). of the Municipality of

Goeke, M. L. (2008). Assess Science. Philadelphia, pr
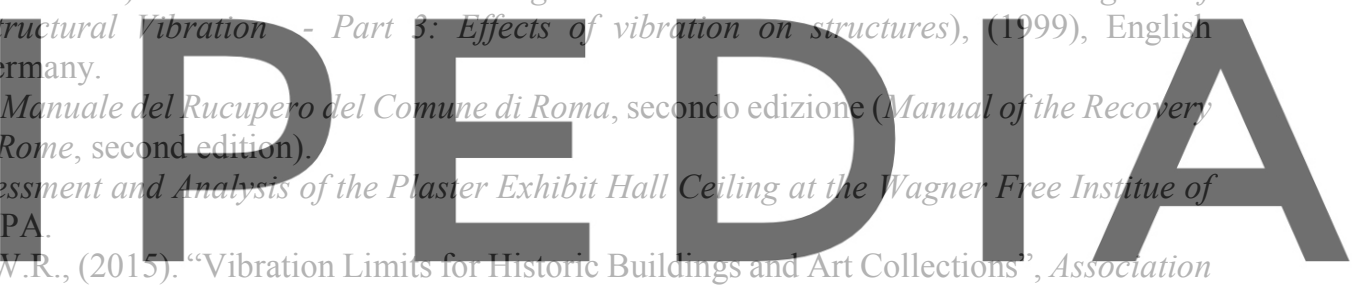
for Preservation Technology (APT) Bulletin, Vol. 46:2-3, pp.66-74.

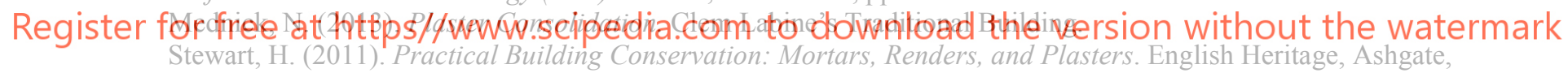
Farnham, England.

Stewart, R (2013). A systematic method for Assessing Wood Lath \& Plaster Ceilings in Historic Churches and Heritage Buildings. Conference for Catholic Facility Managment.

Swiss Association of Road and Transport Experts, Swiss Standard SN 640 312A, Vibration Impacts on Structures, (1992), English Translation. Zurich, Switzerland.

Vitruvius, (c. 25 BCE), De Architectura, English language translation by Morris Hicky Morgan, Vitruvius: The Ten Books on Architecture, Dover, 1960. 